\title{
Iz muzeja literarne arheologije: je tragedija okameneli fosil ali živi dinozaver?
}

Krištof Jacek Kozak

Univerza na Primorskem, Fakulteta za humanistične študije, Titov trg 5, 6000 Koper https://orcid.org/0000-0002-6814-1358

kjkozak@fhs.upr.si

V20. stoletju je enega osrednjih pogledov na tragedijo kot umetniško zurst predstavljala priljubljena hipoteza Georga Steinerja o smrti tragedije. Originalna in prepričljiva je vzbudila vtis, kot da se žanr in z njim povezana človekova izkušnja iztekata. Vobdobju zadnjih petdesetih let, ko se je na uprizoritvenem področju razmahnila postdramska praksa, se je zdelo, da se Steinerjeva hipoteza zgolj potrjuje. Neodvisno od tega pa se je razprava o tragediji ves ta čas intenzivno nadaljevala. Posebej plodovito se je izkazalo prav novo tisočletje, ko so $v$ razpravo o tragediji vstopili teoretiki, kot so Terry Eagleton, Erika Fischer-Lichte, Hans-Thies Lehmann in Simon Critchley. Ne glede na to, da se je tragedije vsak izmed njih lotil s specifičnega stališča - izkustvenega, historičnega, filozofskega ali umetniškega -, je rezultat njihovih ugotovitev enoznačen: tragedija živi tudi danes. Vsvojih analizah, predstavljenih v pričujočem članku, se lotevajo tradicionalnih pojmov, kot so mit in zgod(b)ovina, junak in subjekt, usoda in krivda ter svoboda in nujnost. Iz njih izpeljujejo tezo, da je tragedija - dobesedno ali preneseno - nedvoumno atribut človekovega stanja, saj „človek obrača, bog pa obrne". Tragedija - tudi sodobna - opisuje tisto človekovo stanje, ko se ta odloči za akcijo, njenega izida pa ne pozna. Edino, kar ima, je vera in slepo zaupanje vase.

Ključne besede: literarne zvrsti / tragedija / postdramsko gledališče / tragični subjekt / tragična akcija / usoda / krivda

Velika nesreča - odvisno sicer od gledišča -, ki je doletela tragedijo kot enega izmed najstarejših literarnih žanrov, je bila njena usodna, celo eksistenčna povezava in, posledično, odvisnost od teorije, torej od poglobljenega premisleka o sami sebi; ta je vzniknil že dolgo pred nastankom literarnoteoretske eksegeze, kot neodvisno področje pa so ga dolga stoletja razvijali filozofi, ki so si od Aristotela naprej lastili pravico do izrekanja sodb o tragediji ne glede na dejstvo, da je že Platon pesništvo in filozofijo ne samo nepremostljivo ločil, temveč ju je zoperstavil in prvemu, 
zaradi po njegovem manjše družbene koristi, odrekel pravico do bivanja v družbi. V tem paketu se je znašla tudi tragedija, ki bi se zanjo odločili samo "izobražene ženske, mladeniči in verjetno skoraj večina gledalcev" (Platon 1377; 658d), ne pa starejši, izobraženi in vplivni možje. Ne glede na to eksistenčno omejitev se tragedija ni predala, kot senca pa ji je zvesto sledil tudi razmislek. Tako se je $\mathrm{v}$ času renesanse eksegeza tragedije profilirala, zožila na znotrajliterarno polje in postala stvar estetike, torej forme, in ni več podlegala aksiološkim vprašanjem, ki so zadevala zgolj vsebino. A zanimanje zanjo vseeno ni popuščalo in pred nekaj več kot dvesto leti je tragedija postala edina literarna zvrst, okoli katere se je izoblikovala lastna filozofija, filozofija tragedije (prim. Billings 2 isl.).

Praktično nemogoče je zaslediti literarnega teoretika, filozofa, ali tudi pomembnejšega avtorja, ki bi ne začutil potrebe, da bi se ne izpovedal tudi na temo tragedije kot "najbolj filozofske med umetnostnimi oblikami« (Billings 1). Pričujoči prispevek se bo osredinil na tiste primere razmislekov o tragediji, ki jih je ponudilo novo tisočletje, spoznavnoteoretično pa so prav zaradi svojega predmeta nepričakovani in nenavadni, saj je $\mathrm{v}$ času poststrukturalizma in postmodernizma prišlo do popolnega razvrednotenja človekove subjektivitete kot nosilke za človekov obstoj ključnih vrednot. Gre torej za pregled možnosti razmisleka o tragediji v teoretsko ne samo post-tragičnih, temveč celo antitragičnih časih.

\section{Predigra}

Kot iztočnico vzemimo pomenljivo, a provokativno teoretsko predpostavko, ki si je po več kot dveh tisočletjih poskusov utelesitve tragedije in razpravljanj o njih privoščila nekaj dotlej nezamisljivega in izrekla neizrekljivo: tragedije ni več, umrla je!

To z ene strani blasfemično, z druge pa osvobajajoče mnenje - vsaj za ume, obremenjene s "prisilo" tragičnega kanona - je leta 1961 izrekel francosko-ameriški komparativist George Steiner v delu Smrt tragedije, ki je na mah postalo hkrati odrešitev in prekletstvo razmisleka o tragičnem žanru ter kanonična postavka post-tragiške teorije. Tragedijo, ki naj bi bridko smrt storila nekje z iztekom klasicizma, torej po Racinu, v začetku 18. stoletja, Steiner razume nadvse tradicionalno: kot umetniško obliko, ki »zahteva neizprosno breme božje navzočnosti« (Steiner, Smrt 222), v kateri je človek podrejen nerazložljivi metafiziki (usodi) in se zaradi zavestnega ali še pogosteje nezavednega spora $\mathrm{z}$ njo znajde $\mathrm{v}$ tragičnem položaju. V sodobni družbi pa je (krščanska) transcendenca 
dobra in odpuščajoča in človek razmišlja racionalno, zato je tragično preseženo (prim. Lehmann, Tragödie und dramatisches 566). V takem svetu odpade nerazumljiva, iracionalna moč usode, ki se s človekom nerazložljivo (po)igra(va): "v tragediji ni zemeljskih rešitev« (Steiner, Smrt 185). O tragičnosti se je podobno izrekel tudi Theodor W. Adorno, ko je spregovoril o modernosti. Po njegovem mnenju gre za obdobje, kjer se "tragika [...] raztopi s pomočjo očitne ničevosti pretenzije subjektivitete, ki bi tu morala biti tragična" (cit. v Lehmann, Tragödie und dramatisches 567). In »kjer so vzroki nesreče posvetni, [...] imamo lahko resno dramo, ne pa tragedije "(Steiner, Smrt 14). Po tej teoriji človek kot izolirani subjekt modernizma ali celo ne-več-subjekt postmodernizma samemu sebi ne more biti več tragičen, pa naj bo tragično bivanje kategorija, ki jo je zmogel razviti edino človek. Steinerjevo razumevanje tragedije zapostavlja človeka v njegovi eksistencialni izkušnji, mu jemlje ne samo pravico do, temveč celo zmožnost tragičnega trpljenja, čeprav je človek tisti, ki za to, neodvisno od teorije, še vedno plača $s$ trpljenjem ali celo lastnim življenjem.

Ko je bilo že videti, da si tragedija od zadanega udarca ne bo opomogla, je sloviti teoretik kulture Raymond Williams kot odgovor na Steinerjevo misel objavil knjigo Moderna tragedija (1966) in v njej odločno rehabilitiral idejo tragedije kot zgodovinskega, družbenega, kulturnega, doživetvenega, umetniškega, teoretičnega in filozofskega pojava. Williams v svoji apologiji tragedije kategorično zavrne predpostavko metafizičnosti tragičnega sporočila in moč tragedije ugleda $\mathrm{v}$ individualnem doživljanju tragičnega, ki pa po svoji naravi velja za vse ljudi, je torej raztegljivo na skupnost in izenačljivo z njo. Je pa v tragediji človek udeležen kot paradigmatični, univerzalni Človek: »ključna [...] je predpostavka stalne, univerzalne in $\mathrm{v}$ bistvu nespremenljive človekove narave." (Williams 45)

Williams tragedije ne razume kot, če si sposodimo Lewisovo neblago opazko o Steinerju iz spletnega članka "Man of Sorrows: On Terry Eagleton's 'Tragedy'", »ozko in politično kvietistično", ampak svoj razmislek o njej razširi na vse človekovo ravnanje. Tragedijo je neodvisno od umetniške forme mogoče videti kot ne le renesančni predpisani recept za trpljenje, pač pa kot metaforo človeškega stanja. Po Williamsovem mnenju je bilo za tradicionalno analizo tragedije značilno predvsem, da si je izbirala posamične vidike literarnega oziroma gledališkega fenomena in zato ponujala individualne rešitve, medtem ko bi naj bilo treba tragedijo preučevati kot iz človeka izhajajočo in od njega odvisno kategorijo. Na tej podlagi Williams razvije idejo o tragediji, ki ne more nastati ne v obdobjih družbene stabilnosti ne odprtega konflikta, tem- 
več $\mathrm{v}$ trenutkih političnih prehodov, $\mathrm{v}$ katerih se spreminjajo vrednostni sistemi, ceno za te spremembe in posledično neusklajenost $\mathrm{z}$ družbo pa plačajo posamezniki s svojim trpljenjem oziroma smrtjo. Tako tragedija namesto poenostavljene postane kompleksna, lahko celo kontradiktorna umetniška forma, ki je hkrati individualna in kolektivna, teoretična in izkustvena, metafizična in konkretna, literarna in uprizoritvena, predvsem pa zgodovinska in sodobna, saj je tragiški pomen vselej "tako kulturno kot zgodovinsko pogojen" (Williams 52), to pa obenem pomeni, da "se dejanje izoliranja ekstremnega trpljenja in nato njegovo reintegriranje $\mathrm{v}$ nepretrgan smisel življenja lahko zgodi $\mathrm{v}$ zelo različnih kulturah z zelo različnimi temeljnimi verovanji« (Williams 53). Z drugimi besedami, tragiški fenomen ni vezan ne na čas ne na kraj, ne na kulturo in ne na metafiziko. Edino, kar ga določa, je njen nosilec, človek. Williams sintetizirajoče sklene, da se "tragediji [...] približamo po številnih poteh" (Williams 13), med katerimi pa poudari polja, v okviru katerih se tragiška eksegeza že stoletja izvaja: izkustveno-psihološko, zvrstno-zgodovinsko, filozofsko-teoretično in pa umetniško-uprizoritveno.

Čeprav je na Slovenskem tragedija razmeroma stara odrska, torej dramska (omenimo le Linhartovo Miß Jenny Love) in teoretična gostja (pojem je "zaduhtel« že v Cvetju slovenskega pesničtva Ivana Macuna leta 1850 , prim. Kos, »K vprašanju« 1996), je v sodobnosti tehtnejši premislek v svojih člankih »Problem slovenske tragedije (1976) ter "K vprašanju o bistvu tragedije (1996) oblikoval komparativist Janko Kos. Prvič je Kos v svoji definiciji tragedije izhajal iz predstave o njeni tradicionalni obliki (zunanja podoba) in vsebini (ustrezni zaplet), ki da edini pogojujeta njen obstoj. Pri veliki večini besedil, tudi takšnih, ki nosijo to ime, po njegovem mnenju ne gre za čiste tragedije, pač pa »za poltragedijo, kvazitragedijo« (Kos, »Problem« 730), ali »melodramsko ali celó moralitetno zvrst" (Kos, "Problem« 732). Po Kosu je popolno tragedijo oblikovala šele renesansa (na primer J. C. Scaliger), razpadati pa naj bi začela $v$ začetku 18. stoletja. Odtlej je bila zaradi njene povezave $\mathrm{z}$ metafiziko njena nemožnost vse očitnejša, zaradi tega pa je nismo ustvarili tudi na Slovenskem. V svojem drugem, že bolj na bistvo tragedije osredotočenem prispevku, Kos z navezavo na Hegla kot temeljni razločevalni princip za prepoznavo in določanje tragedije domišljeno vpelje smiselno konceptualno dvojico legitimnosti in legalnosti. Čeprav tu Steinerja omeni le enkrat, teoretiku sledi z enako ugotovitvijo kot prvič, in sicer da je tragediji kot umetniškemu fenomenu navček že zapel.

Načelno soglasje s Steinerjem je podala tudi slovenska komparativistična stroka. Ob izidu prevoda Smrti tragedije (2002) je Slovensko društvo za primerjalno književnost januarja 2003 priredilo pogovor o 
besedilu (vodil ga je Vid Snoj, sodelovali pa so J. Kos, Lado Kralj in Gorazd Kocijančič,), v katerem so bili sodobni pogledi na tragedijo jasno predstavljeni, dvomi pa ne odpravljeni. V diskusiji se je namreč jasno izrazilo problematično dejstvo Steinerjevega »odprtega« konca, saj je Steiner v Smrti tragedije formiral tri možne "usode« tragedije: njeno smrt, nadaljevanje ter celo ponovni vznik. Pri slednjem je kot primer prave moderne tragedije določil Büchnerjevega Vojčka, kar je, nota bene, povzročilo precej preglavic tudi diskutantom ob slovenskem prevodu. Ali bi torej, ne glede na njeno deklarirano smrt, dejansko obstajala vera v možnost preživetja tragedije? Tej opciji je bil še najbolj naklonjen filozof G. Kocijančič, po čigar mnenju je dopustno razmišljati o možnostih njenih metamorfoz, pri čemer je pomembna ugotovitev, da "potencial tematizacije tragičnega» (Snoj et al. 105) tudi danes še ni izčrpan.

Zanimivo je, da se je k tragediji še večkrat vrnil tudi Steiner sam, vendar z enakim izidom. Denimo v članku "A Note on Absolute Tragedy" (1990) je parafraziral Sofokla iz Ojdipa na Kolonu: absolutna tragedija je v "zločinu človeka, da je, da obstaja» (147), iz česar pa je izpeljal že znani zaključek o nemožnosti tragedije.

\section{Živa zvrst}

Steinerjeva osmrtnica za tragedijo je še bolj podčrtala prepad med tradicionalnima nasprotnicama - tragedijo in teorijo. Ne glede na to pa je na začetku tretjega tisočletja razmislek o medsebojnem razmerju med tragedijo resničnega življenja in umetnosti dobil silovit pospešek ob soočenju zahodnega sveta z grožnjo terorizma, kakršno je predstavljal na primer teroristični napad na newyorška "dvojčka». Tako je skoraj čez noč tragedija postala spet (tragično) modna in moderna. Kot nekoliko oddaljeni, a neposredni odmev njujorških dogodkov iz 2001 je revija New Literary History leta 2004 objavila številko pod naslovom Rethinking Tragedy, kjer so sodelovali ključni sodobni teoretiki tragedije, med njimi tudi številni tu omenjani: G. Steiner je prispeval članek z naslovom »"Tragedy' Reconsidered ", Simon Critchley »I Want to Die, I Hate My Life - Phaedra's Malaise", Terry Eagleton pa je zbrane prispevke pospremil s sklepnim komentarjem (Eagleton, "Commentary«). Izkazalo se je, da je tragedija zelo vitalna, dinamična, predvsem pa aktualna družbena in umetniška kategorija. 21. stoletje je tako uresničilo ne Steinerjeve, pač pa Williamsove napovedi. Ne samo da tragedija ni umrla, ampak se je je oživljena teorija lotila iz vseh mogočih zornih 
kotov, kot so inherentna tragičnost, razmerje do vseobsegajoče usode ter miti in zgod(b)ovina.

Enega prvih poskusov novega tisočletja, kako sumarno odgovoriti na vprašanja o tragičnem, predstavlja izkustveno-psihološko in filozofsko delo odmevnega angleškega literarnega teoretika T. Eagletona Sweet Violence: the Idea of the Tragic (2003). Eagleton je v njem idejo o moderni tragediji utemeljil na pomembnem spoznanju: svobodi sodobnega subjekta $\mathrm{v}$ kontingentnem kronotopu. Moderna tragedija obstaja in se od antične razlikuje po tem, da danes svoboda pomeni absolutno "nezavedanje nujnosti« (Eagleton, Sweet Violence 204). Sodobni človek je odvisen od dveh predpostavk: svobode, ki je premo sorazmerna z naključnostjo življenja, ter "realnosti časa" (220), ki pa je sploh izvorni medij za uresničenje tragedije. Skoznjo lahko tragedija na podlagi želje (tolikokrat neuresničene, ker je v osnovi neuresničljiva) vstopi v naša sodobna življenja. Naj je tragičnost sodobnega človeka še tako banalna, to ne spremeni dejstva, da je za subjekt popolnoma prava tragična izkušnja. Ta ugotovitev je tudi Eagletona pripeljala do uvida o temeljnem razkolu med teorijo tragedije in njeno umetniško uresničitvijo. Medtem ko po njegovem teorija vztraja pri zagledanosti v koncepte časti, hierarhije in heroizma, mita, večnosti in bistva, se današnji svet sooča $\mathrm{z}$ veliko bolj vsakdanjimi pojavi, ki bi tudi za antično tragedijo nedvomno predstavljali ustrezno snov. Eagleton se zato odloči za Steinerjevo drugo opcijo: v sodobnosti je človek spet postal igrača ne usode, pač pa družbeno-ekonomskih razmerij, ki nanje lahko seveda vpliva natanko toliko kot na usodo (to spoznanje so pogosto potrjevali kulturologi, sociologi in filozofi kot na primer Raymond Williams, Zygmunt Bauman, Giorgio Agamben in drugi). Tako uspe Eagleton združiti dve na videz neskladni obliki tragedije: antično in sodobno, saj obe predstavljata upor zoper usodo/družbeno danost/pasivni kozmos in ne privolitve vanje, $s$ čimer preseže Steinerjevo ozko razumevanje ali, kot je to izrazil že Williams: „Različice tragiške izkušnje je treba interpretirati z ozirom na spreminjajoče konvencije in institucije» (Williams 46) današnjega sveta.

Dejansko filozofija tragiške teorije Steinerja niti ni pretirano resno jemala. Dokaz za to je delo nemškega filozofa in germanista Christopha Menkeja Die Gegenwart der Tragödie: Versuch über Urteil und Spiel (2005). Ne glede na naslov je treba ugotoviti, da gre pri proučevanju »igre« $\mathrm{z}$ namenom analize besedil (na pokušino Menke ponudi Hamleta, Beckettov Konec igre, Filokteta Heinerja Müllerja ter Itako Botha Straußa) zgolj za tekstno analizo in ne za členjenje njihovih uprizoritvenih razsežnosti. Menke že v izhodišču zavrne idejo, da bi bila 
modernost lahko sploh čas brez tragedije. Sodobnost predstavi namreč kot obdobje, v katerem ljudje še najsvobodneje presojamo, pri čemer kolikor svobodneje oblikujemo svoje sodbe, tem bolj in vse pogosteje se (lahko) tudi znajdemo v položaju, ki ga moramo označiti kot tragičnega. Vendar tragično - in tu se Menke pokloni umetniški tragediji brez umetniškega prečiščenja v obliki tragične drame še ni resnična tragedija. Šele njena predstavitvena razsežnost je zares "pogoj spoznanja tragedije (Menke 107). To velja za oba modela tragedije, klasičnega in modernega: pri klasičnem se tragika izpostavi v lepoti estetskega, medtem ko se pri moderni različici določi anti-tragična razsežnost tragedije skozi gledališko igro, pri kateri smo kot gledalci soudeleženi z refleksijo razlik in posledično ironije. Kajti tragedija je - zaradi gledališke izvedbe - "avtorefleksivna", kot gledališče se nanaša sama nase, kar Menke na podlagi Aristotela dokazuje z upoštevanjem gledalčeve reakcije. Uprizoritvena razsežnost tragedije pa je tako pomembna zato, ker estetski filter umetnosti očisti tragično odvečnega življenjskega balasta in ga prikaže $\mathrm{v}$ prečiščeni luči. $\mathrm{V}$ moderni tragediji se zoperstavita dve obliki delovanja: »izkušnja tragike je izkušnja delovanja, ki je podrejeno moči usode; izkušnja estetskega pa je nasprotno izkušnja delovanja, ki razgrinja svobodo igre (Menke 134-135). Nova določitev estetskega se $\mathrm{v}$ sodobnosti tako spoprime $s$ tragičnim, toda bistvo tragedije kot fenomena je, da v ravnovesju vzdržuje oba. Če ne bi bilo te uravnoteženosti, bi estetsko lahko odpravilo tragično in utelesilo netragični čas (in človeka). Tu pride pa do ključnega obrata: igra na sebi izkaže svojo nemoč, $s$ čimer odpre prostor za vrnitev (v spremenjeni obliki sicer) tragedije, kajti "gledališč tragedije estetsko določi tragiko tragedije» (134). Menke teoretično določi gledališko uprizoritev, tragedijo igre, kot metagledališče oziroma metatragedijo (prim. 155 isl.). To pomeni, da gre za tragedijo po tragediji, povratek tragedije skozi gledališče oziroma, da ni "tragedija iz ničesar drugega kot gledališča, tragedija iz teatralnosti« (156). Ne glede na predpostavko ontološke teatralnosti sodobne tragedije pa je treba ugotoviti, da pri Menkeju vendarle ne gre za postdramske uprizoritvene kvalitete, iz katerih je kasneje izhajal Lehmann.

Menkejev nekoliko hermetični pogled na tragedijo si ne prizadeva, da bi vstopil v dialog z doslejšnjimi osrednjimi razmisleki o njej, pač pa ponuja naslednji, novi primer filozofije tragedije. Težava s filozofskim pristopom $\mathrm{k}$ tragediji pa je $\mathrm{v}$ tem, da se, kot pri premisleku o različnih vidikih žanra, teoretiki ne morejo zediniti glede izhodišč same "teorije o teoriji«, kakor jo uvodoma imenuje Billings, kaj šele glede njene vsebine. Se pa s filozofijo tragedije teoretiki lahko ukvarjajo tudi taksonomično, pri čemer konstruirajo razvojni lok tragiške filozofije v odvisnosti od 
svojega individualnega zrenja. Zgolj za ilustracijo takšnega pristopa je mogoče navesti delo Juliana Younga The Philosophy of Tragedy: From Plato to Žižek (2013).

Svojo eklektično in hkrati nujno arbitrarno kolekcijo pogledov na tragedijo Young začne $\mathrm{z}$ naslednjo samoumevno zvenečo trditvijo: "Filozofija tragedije se prične s Platonom « (Young 3). Na svojem izletu po bližnjicah filozofske misli o tragediji se Young mimo Aristotela sprehodi v Rim do Seneke, na kratko ustavi pri Humovi diskusiji o francoskem (klasicističnem) tragiškem ugodju, dlje časa pa se zadrži pri nemški predromantiki in idealizmu. Osredotoči se na osrednje tragiške kategorije ter njihova razmerja: svobodo in nujnost, treznost in opijanjenost, konflikt in spravo. Posebej denimo opozori, da Hegel zavrne pomen sprave, kakor ga je razvil Schelling, in se s svojim razumevanjem precej približa prijatelju iz študijskih časov, Hölderlinu. Heglovo videnje antične tragedije je namreč precej bolj aristotelovsko, saj v svoji substancialnosti ne vidi usode, ki bi kaznovala nič hudega slutečega posameznika, ampak slednjemu pripiše aktivnost, na podlagi katere se ta znajde $\mathrm{v}$ tragičnem položaju in si tako - brez krivde kriv - pravzaprav usodno kazen prisluži.

Nadaljnjo pozornost nameni Young sodobnejšim razmislekom od tragediji, ki se iztečejo $\mathrm{v}$ začudljivo preprosto, a ravno zaradi svoje enostavnosti le stežka sprejemljivo tezo: "tragedija je zelo žalostna zgodba" (Young 263). Čeprav lahko skrajna simplifikacija definicij privzame v stanju njihove popolne zapletenosti funkcijo meča pri gordijskem vozlu, ta v primeru tragedije ne doseže svojega namena. Tradiciji tako žanra kot njegove teorije sta prebogati, da bi ju bilo mogoče odpraviti zgolj s tapeinozo.

Zvrstno sicer podoben, le bolj poglobljen, logičen in koncizen je poskus Joshue Billingsa Genealogy of the Tragic: Greek Tragedy and German Philosophy (2014), ki se liminalno dotika dveh področij: izhaja iz zgodovinske obravnave tragedije, da bi se natančneje posvetil njenim filozofskim predpostavkam. Raziskovalno ambicioznejši in bolj sistematičen je Billings zato, ker se posveti samo enemu - sicer ključnemu obdobju genealogije (v Nietzschejevem smislu) filozofske tragiške misli, nemški klasiki, znotraj katere si je po svojih besedah prizadeval razkriti doslej še ne zaznane povezave in miselne afinitete.

Billingsova obravnava moderne tragedije se naslanja na nemški endemični koncept iz časa razsvetljenstva, in sicer filohelenizem ali grkofilijo. Nemčija se je namreč v polovici 18. stoletja začutila dedinjo visoke antične kulture, ki jo je začelo njeno uveljavljajoče se meščanstvo navdušeno sprejemati. Eden izmed ključnih konceptov za ta proces 
in tudi za na primer Lessingovo meščansko tragedijo je bil pojem antične usode. Billings tako izhaja iz Schellingove razprave o tragediji iz Filozofije umetnosti, kjer se v ospredju znajde vprašanje posledic usode, ki je $\mathrm{v}$ tesni zvezi z učinkom tragedije in katarzo, ta pa je spet tesno povezana s spravo. Tragična sprava, čustvena harmonija sta kultiviranim Nemcem predstavljali dokaz "o absolutni zvezi svobode in nujnosti« (Billings 127), torej razmerja med človekom in usodo kot na človeka neobčutljivo dejanskostjo. Sprava je postala osnovni problem miselne konstrukcije tragedije $\mathrm{v}$ krščanskem horizontu predromantike in idealizma zaradi svoje (ne)možnosti udejanjenja. Takrat si namreč ni bilo mogoče predstavljati sprave kot posledice tragičnega trpljenja, zaradi česar se pojmu usode odrečeta tako Hölderlin (modernost je brez usode, ki naj bi umanjkala že pri Shakespearju) kot Hegel (njeno mesto podeli substancialnosti). Heglova substancialnost ima sicer kar nekaj značilnosti antične usode, najpomembnejša razlika med njima pa je, da je substancialnost pravzaprav etična. In če je bilo za Aristotela pri določanju tragične osebe ključno njeno delovanje, je pri Heglu to značaj, čigar cilj je pa enak cilju substancialnosti. Substancialnost je po Heglu tudi pravi predmet tragedije, ker v sebi združuje človeško in »božansko« zavest, kot taka pa je lahko le singularna, enovita kategorija. Na tej podlagi Hegel sploh lahko utemelji svoj pojem sprave, saj bi bil ta brez vrnitve k sebi neverodostojen.

Billings s svojo razlago nasprotuje poznejši Steinerjevi uporabi krščanstva pri utemeljevanju propada tragedije. Steiner se je namreč tega problema dobro zavedal in je krščanstvo razumel kot dokaz transcendentalne nemožnosti tragedije. Billingsova študija pa nasprotno pokaže, da so bili nemški teoretiki veliko bližje povezavi krščanstva in tragedije, kot bi bilo mogoče sklepati. Po Schellingovem mnenju bi bilo namreč mogoče razumeti Ojdipa kot neke vrste Kristusa, Ojdipovo krivdo pa kot felix culpa, s katero je - podobno kot Kristus - odrešil človeštvo (prim. Billings 87). Je pa spet res, da to ni izvedljivo v dejanskosti, pač pa zgolj v estetski sferi, saj bi sicer človek privzemal božanske atribute. Podobno je na problem gledal tudi Hölderlin: "paradigmatična figura Schicksal je Jezus, človeški lik, čigar žrtev je vzpostavila razmerje med človekom in bogom" (Billings 140). Hölderlinovemu teološkemu zrenju na tragedijo se je navsezadnje po Billingsu v Fenomenologiji duha pridružil tudi Hegel, le da se, glede na to, da sta oba zanikala usodo, tragedija Heglu izkaže kot "ključni trenutek na poti duha" (Billings 187), kot »oblika duhovne sprave« (165), ki pa ima vse predpostavke religiozne sprave. Težko bi našli prepričljivejšo misel, ki bi hipotezi o smrti tragedije učinkoviteje obrusila zobe. 
$\mathrm{Na}$ Billingsovo intrigantno študijo se $\mathrm{z}$ obravnavo filohelenistične predpostavke naveže delo osrednje nemške teatrologinje, germanistke in komparativistke Erike Fischer-Lichte Tragedy's Endurance: Performances of Greek Tragedies and Cultural Identity in Germany since 1800 (2017). Njeno izhodišče je zgodovinska in umetniška zgostitev nemškega kulturnega življenja okoli filozofskih in umetniških idej antične tragedije $\mathrm{v}$ času (pred)romantike in filozofskega idealizma, ki sta danes že nesporno obveljala za enega ključnih trenutkov v eksegezi tragiškega fenomena. Fischer-Lichte namreč potrdi Billingsovo opredelitev povezanosti nemške (pred)romantike s fenomenom filohelenizma, ki je bil že od vsega začetka pogojen z izrazito razsvetljenskim občutenjem, kakršno se je razvilo okoli sredine 18. stoletja: leta 1755 je namreč izšel traktat J. J. Winckelmanna Gedanken über die Nachahmung der griechischen Werke in der Malerey und Bildhauerkunst, ki je po FischerLichte ubesedil težnje omikanega meščanstva [Bildungsbürgertum]. Novi vrednoti meščanskega razreda, ki ju je Wincklemannovo besedilo poudarilo in s tem občutljivo zaznalo novega družbenega igralca, sta bili »'plemenita preprostost' in 'tiha veličina' « (Fischer-Lichte 8), s katerima je meščanski razred načrtoval stopiti ob bok aristokraciji.

Nemški razsvetljenski sistem vrednot si je ustvaril sliko grške antike, ki je temeljila na »brezupni strasti do absolutnega» in »nevarnem idealizmu« (Fischer-Lichte 1). Vse močnejši, mladi nemški meščanski razred je verjel, da lahko postane velik le s posnemanjem antike. Zato najbrž ni naključje, da se je isti čas zgostilo tudi dogajanje okoli tragedije. Svojo prapremiero je namreč leta 1755 doživela tudi prva domača meščanska žaloigra: Lessingova MißSara Sampson (prim. Fischer-Lichte 7). Cilj je bila seveda najvišja kvaliteta človeškega značaja, sočutje, kar dokazuje tudi Lessingova definicija tragedije: »Pomen tragedije je ta: razvije naj našo sposobnost, da občutimo empatijo (Fischer-Lichte 9). S tem, ko je prevzelo vlogo "javnega foruma" (12), je nemško gledališče v tem času prevzelo ključno vlogo spodbujevalca sočutja in $s$ tem tudi vsesplošne občutljivosti človeškega značaja ter omike. Postalo je osrednji člen pri oblikovanju samozavesti novega razreda, saj je bilo pričakovano, da bo gledališče zagotovilo "manjkajoči občutek harmonije« (13).

Ker gre pri tovrstnem izobraževanju naroda za dolgotrajen proces, je tudi lažje razumeti, da je grkofilija vztrajala več kot dve stoletji, kolikor je obsegala tudi nemška fascinacija $\mathrm{z}$ antično tragedijo - ideologija omikanega meščanstva naj bi uplahnila šele okoli 1980 (prim. FischerLichte 313). Omeniti velja, da sta oba občutka spet radikalno vzniknila $\mathrm{v}$ času nemške družbene krize, v dvajsetih in tridesetih letih 20. stoletja, ko se je nemška omika povezala z družbeno čistostjo in, posledično, z 
rasizmom (Fischer-Lichte 313). Analiza sodobnega nemškega gledališča pa pripelje Fischer-Lichte do zaključka, da po več kot dvesto letih intenzivnega nemškega ukvarjanja z vprašanjem tragedije razkola med posameznikom in skupnostjo - ne glede na žrtev prvega - ni mogoče spraviti. $\mathrm{Na}$ vprašanja, ki jih je sodobnosti zastavila romantika, po raziskovalkinem mnenju ni mogoče zadovoljivo odgovoriti in to kljub mislecem Heglovega kova. Tragedija je tako vedno kritika družbenih razmerij in kot taka še izjemno živa. Zato Fischer-Lichte svoje delo sklene z zaključkom, ki spominja na poznega Steinerja, in sicer, da je »človekovo stanje treba ugledati kot tragično" (325).

Tragedije kot umetniškega fenomena se je v svojih filozofskih, predvsem pa gledališko-praktičnih diskusijah (»Postdramatische Tragödie. Anmerkungen zum Theater von Tadeusz Kantor " ter "Tragödie und postdramatisches Theater", 2007; "Tragödie und Performance", 2009) loteval tudi H.-T. Lehmann in to celo po tem, ko je leta 1999 s svojim Postdramskim gledalǐ̌čem kanoniziral novo kategorijo uprizoritvenih umetnosti. Temo tragedije je okronal leta 2013 z več kot 700-stransko razpravo Tragödie und dramatisches Theater, ki predstavlja pravzaprav diderotovsko enciklopedično ambicijo, kako izkušnjo tragedije prenesti na najsodobnejšo prakso uprizoritvene umetnosti: postdramsko gledališče.

Tragedija tudi po Lehmannovem mnenju seveda ni umrla - o(b) staja še naprej, vendar v popolnoma neskladni obliki z doslejšnjo tragiško teorijo in prakso. Njegov pristop je odločen in samo še opozori na raztrganino med besedilom in uprizoritvijo, ki jo razume kot umetni razkol med tragedijo in gledališčem. Po njegovem mnenju je malodane celotna doslejšnja teorija tragedijo določala na podlagi vsebine, jo reducirala zgolj na literaturo in se obnašala, kot da gledališče tragedije ne bi obstajalo (prim. Lehmann, Tragödie und dramatisches 16), s tem pa negirala tudi dejansko doživetje tragične izkušnje. V doslejšnji teoriji tragedije je bilo po njegovem doživetje tragičnega vedno pripisovano duhu, torej je bilo predvsem misljivo, medtem ko je užitek ob formi ostajal (manjvredni) umetnosti. Tragediji šele gledališka gesta zares omogoči, da zasije - seveda ne kot heglovska ideja - v svoji bogati sporočilnosti in dobi pomenljivo družbeno razsežnost. V svoji teoriji tragedije se zato Lehmann osredotoči na uprizoritveno plat dramske umetnosti, saj »brez gledališke izkušnje ni namreč nikakršne tragične izkušnje« (18).

Glede na neizogibno kategorijo teatralnosti določi Lehmann tri razvojne faze tragedije: preddramatično (antično), dramatično (renesančno in klasicistično) ter postdramatično (sodobno), ki pa hkrati izražajo tudi bistvo vsakokratne različice tragičnega. Čeprav gre vsakič 
za novo, posebno in zgodovinsko specifično izraženo tragično, naj bi obe pretekli obliki tragedij že vsebovali potencial za njeno sedanjo različico, pri čemer Lehmann opozarja, da sodobna različica estetske tragiške izkušnje ni neposredno in avtomatično nadaljevanje predhodnih.

Ta hipoteza, ki ni brez odmeva Heglovih stopenj razvoja umetnosti, se odkloni od teorije tragedije in pristane pri teoretiziranju njene gledališkosti (o tem se je nekoč razpisal že Aristotel) in uprizorljivosti. Vendar Lehmann ni pristaš teze, da bi bilo »tragično [...] kratko malo [...] identično z estetskim fenomenom" (Lehmann, Tragödie und dramatisches 60), saj sodi, da pojmi "protislovje, paradoks, konflikt in 'kolizija' «(60) sami na sebi niso tragični, temveč jih za takšne naredi naša refleksija. Tragični fenomen kot estetska kategorija torej ni nujno že resničnost eksistence na sebi, temveč se izrazi kot prekoračitev oziroma transgresija, ki je seveda lahko samo uprizoritvena (in ne diskurzivna): »tragično je modus umetniškega odpiranja sveta (64; avtorjev poudarek), kar Lehmann predstavi kot eksces: »eksces pripravljenosti na smrt ali žrtvovanje, eksces raziskovanja, eksces samouveljavljanja« (99). Eksces je mogoče ugotoviti tako pri antičnih kot tudi renesančnih junakih, ki prekoračujejo svoje nravstvene pozicije in presegajo (kršijo) zakon.

Kaj pa tragedija danes? Po Lehmannovem mnenju živi - celo zelo dobro - naprej. Lehmann se ne strinja s Steinerjevo razsodbo o smrti tragedije na podlagi metafizične razsežnosti sveta, češ da se je današnji svet metafiziki že zdavnaj odrekel. Zato metafizike ni mogoče še naprej resno upoštevati kot osnove za razmislek o tragediji, to pa razblini Steinerjev argument. V današnjem času govori v prid tragediji tudi oslabljena prisotnost racionalnosti v svetu, v katerem se je razsvetljenski ideal dokončno razkrojil, njegov prostor pa so zasedli darvinistični goni sebičnosti, brezobzirnosti in drugih podobnih človekovih »vrlin«. Zato je tragedija kot dramsko besedilo za Lehmanna le še »literarni muzejski kos" (Lehmann, Tragödie und dramatisches 585). Če hočemo tragedijo zares razumeti, je potrebna zamenjava miselne in izkustvene paradigme. Tragedijo je Lehmann, ločeno od drame, sicer ohranil, a premaknil na historično vzporedni, doslej zanemarjani tir uprizoritvene razsežnosti, v teatralnost. Tu je sicer že ves čas obstajala, a jo je primat gledališkega logosa vselej zapostavljal. Današnja estetska tragedija se po Lehmannu ne uteleša več kot dramsko besedilo, ki je v postdramskem času izgubilo svoj primat, pač pa kot uprizoritvena razsežnost gledališča, zaradi česar je tragedija pravi postdramski žanr.

Naj se zdi Lehmannov argument še tako (pre)napet, pa njegov očitek, da je v diskusiji o tragediji večino časa teorija prevladovala nad prakso, ni čisto brez podlage. Teorija tragedije je uprizoritveno razsežnost 
tragiških besedil dejansko zapostavljala - če natančno premislimo, je na to opozarjal že Aristotel - predvsem zaradi poudarka na družbeni, torej etični in politični sporočilnosti. Tako je bila tragedija razumljena kot "najbolj filozofska med umetnostnimi oblikami« (Billings 1), ki je »kaj" postavljala pred »kako«. Mestoma, in tu jo zadane Lehmannova kritika, je postala do te mere samozadostna, da se je spremenila že $\mathrm{v}$ "preiskavo o preiskavi, kar nas je speljalo stran od fenomena samega "(Billings xi). Kolikor izraziteje se je Lehmann izrekal o izključnosti praktične tragedije v postdramskem času, tem opazneje se je izrisovala razlika med sodobno gledališko prakso in teoretičnim razmislekom o tragediji, ki pa se v večini primerov nadaljuje v tradicionalni teoretični smeri. Dokaz za slednje sta dve publikaciji najmlajšega datuma, obe izpod peres angleških teoretikov.

Kot prvo naj navedemo nekonvencionalen, a prepričljiv poskus britanskega zvezdniškega filozofa Simona Critchleya Tragedy, the Greeks and Us (2019). Critchley se tragedije loti brez kakršne koli zgodovinske obzirnosti ali poklona predhodnim avtoritetam, njegov razmislek pa velja predvsem ideji tragedije, torej njeni (meta)vsebini. Saj tudi ne more biti drugače, kot opozarja, ker je prvi pomen starogrške besede $\theta \varepsilon \omega p i ́ \alpha$ [theoria] ravno "gledanje slavnostnih iger" (Dokler 365). Zato je "teater vedno teoretičen in teorija je teater, $v$ katerem smo gledalci drame, ki se odvija (Critchley, Tragedy 6). Na podlagi te semantične igre oblikuje pomisel, da tragedija predstavlja "mišljenje $v$ delovanju [thinking in action], razmišljanje o delovanju, zavoljo delovanja« (5; avtorjev poudarek), s čimer se spet znajde toliko znotraj konvencionalne sfere diskurza o žanru, kot tudi zunaj nje. Critchley namreč tragedijo ubrani pred nevarnostjo večine doslejšnjih eksegez, jo izmakne ustaljenim pastem klasičnih omejujočih kategorij in posveti nanje $\mathrm{z}$ lučjo običajne človeške izkušnje. Po njegovem mnenju tragedija izkazuje brezčasno in vsesplošno človeško stanje, za katerega sta značilni "težavnost in negotovost delovanja v svetu, ki ga definira dvoumnost" (5; avtorjev poudarek). Žanr se mu ponudi kot povečevalno steklo, $s$ katerim si lahko ogledamo meandre in pasti na poti svojega življenja, kar je mogoče brez nadaljnjega izenačiti s pojavom, ki so ga stari imenovali »usoda" (prim. Critchley, Tragedy 3 isl.). »Usodnost « je namreč tisti razkorak, ki se pojavi med teorijo in prakso našega življenja, saj ni človeka, ki bi poznal svojo prihodnost in si ne bi zastavljal vprašanj o svojem bivanju oziroma delovanju. Zato nedvomno velja Critchleyeva ugotovitev, da si mora odgovore na svoja vprašanja v tragediji poiskati vsaka doba, vsak človek zase. Odgovorov, ki bi veljali za vse čase, prostore in ljudi, preprosto ni. 
Critchleyevo izhodišče predstavlja dvanajst tez o tragediji, med katerimi je med bolj izzivalnimi enajsta: "Tragični junak je problem, ne rešitev problema" (Critchley, Tragedy 34). V delu svoje razprave, namenjenemu tragični krivdi, se Critchley izogne tradicionalni heglovski dikciji o krivdi brez krivde ter opozori, da ne glede na poimenovanje, tragedija ni nesreča. Se pravi, ne more obstajati zavest o junakovem delovanju, ki bi mu že vnaprej (avtomatično) pripisovala neko vrednost. Tragedije zato ne moremo razumeti kot »nesreče«, pa naj bo zavestna ali nezavedna. Ojdip, na primer, je poznal svojo prerokbo. Nihče ga tudi ni silil v silovit obračun z neznancem na križǐšču; do njega je prišlo v samoobrambi. Tragedija je zato po Critchleyu namenjena samospoznanju, ovrednotenju lastnih dejanj, toda šele po tem, ko se objektivno razjasni njihova vrednost. In problem je v tem, da se običajno izkaže, da v tovrstnih spopadih zmagovalca ni, da je pravica na obeh straneh. Obe strani sta torej enako (ne)krivi, s čimer se Critchley tako rekoč neposredno naveže tudi na Kosovo misel o spopadu med legalnostjo in legitimnostjo, dvema aksiološko enakovrednima kategorijama. Zato je treba tragično iskanje in vzpostavljanje pravice razumeti kot konflikt (prim. Critchley, Tragedy 25), sprava pa ni mogoča, saj tertium non datur.

$\mathrm{V}$ tragediji je pravica deljena oziroma ker se previja iz ene pozicije $\mathrm{v}$ drugo in nazaj, lahko rečemo, da sta pravičnosti pravzaprav dve, ali drugače, da je pravičnost na strani obeh. Dejavnost pa, ki gledalcu omogoči spopad z izmuzljivo pravičnostjo, je na sledi delovanja junaka/ junakinje $\mathrm{v}$ obliki racionalnega tehtanja, preverjanja, presojanja njegovih/njenih stališč, pa naj so naše cerebralne sposobnosti še tako omejene. Predstavlja namreč »racionalno uprizoritev ali reapropriacijo mitičnega rituala v kontekstu nove estetike« (Critchley, Tragedy 38; avtorjev poudarek), torej v okviru mimesis. Izjemno dobro je to predpostavko mogoče dokazati v Kralju Ojdipu, saj se gledalci nagibajo enkrat $\mathrm{v}$ eno in drugič $\mathrm{v}$ drugo stran, odvisno od predstavljanih argumentov, vse dokler zadnji kamenčki mozaika ne zapolnijo spoznavne vrzeli in odpravijo vsakršen dvom o dejstvih (ne pa krivdi). V Ojdipovem primeru pa lahko $\theta \varepsilon \omega \rho o ́ \varsigma$ (theorós, gledalec) Sofokleju sledi še v drugo zgodbo, kjer je "kriminalnemu" kršilcu božjih zapovedi navsezadnje odpuščena vsakršna kazen. A ta sprava ni ne hegeljanska ne religiozna.

Critchley na podlagi navedenega opozori namreč na prevelik pomen, ki ga je v tragediji kasnejša analitična tradicija pripisala spravi in s tem imanentno religiozni razsežnosti. Kakor tragedija na sebi ni bila mit, tudi ni bila ritual in zato ne more biti podvržena logiki religioznosti, ki je osnovana na sklepni pomiritvi konflikta. Slednje v tragediji ne more 
biti, saj je za Critchleya njeno bistvo prav nasprotno: tragedija razpira svet dvoumnosti in neskladja. Razplet ne pomeni sprave, temveč nadaljevanje spora, ki ga omogoča obojestranski prerogativ pravičnosti. In šele tako se izkaže, kako lahko tragedija zares odzrcali našo eksistenco in postane mimesis našega univerzuma. Temeljni princip našega sveta, ki je ujet $\mathrm{v}$ entropijo, je konflikt in tragična je tista zavest, ki se tega $\mathrm{v}$ polnosti zaveda. Tragedija torej principielno ni umetnost, temveč ozaveščena oblika naše eksistence.

Druga knjiga pa je še čisto "sveža«, saj je izšla v zloglasnem koronskem letu 2020 - realnost tega leta grozljivo spominja na tebansko pandemijo, le da s to razliko, da so takrat Tebanci dobili rešitelja v Ojdipu. Delo T. Eagletona z razmeroma nezapletenim naslovom Tragedy je že njegova druga knjiga (sic.) na temo tragedije.

Če je bil v svoji prvi knjigi o tragediji - kakor smo zabeležili zgoraj - Eagleton spoštljiv do žanra na sebi, ga skuša tu obravnavati bolj sproščeno. Izogniti se hoče tradicionalnemu, esencialističnemu, vrednostnemu, tudi konservativnemu (torej steinerjevskemu) pristopu in tragedijo podvrže bolj neobremenjenemu pogledu. Manj apriorno inovativen kot Critchley, Eagleton stopa v dialog s predhodniki v analizi tragedije, ki je tudi po njegovem videnju v bistvu umetniška (literarna in uprizoritvena) ustreznica sodobnemu svetu. Eagleton podpira tezo, da je tragična zvrst tipična za tranzicijska obdobja ( $v$ tem je podoben Heideggerju, prim. Eagleton, Tragedy 86), se pravi za liminalni čas, ko se podira stari in izgrajuje novi svet, kar razpira poseben kronotop, ki bi ga lahko poimenovali "ne več in še ne«. Eagleton sicer ne gre tako daleč kot Critchley, da bi v tragediji videl stanje dvoumnosti, nedorečenosti in stanje dveh pravičnosti, vseeno pa tragedija prvenstveno izhaja iz polisa, ki ga občasno v njegovi racionalnosti omeji mit. Uteleša "neizrazljivo v srčiki družbenega ali diskurzivnega reda" (Eagleton, Tragedy 87), koketira $\mathrm{z}$ omejevanjem političnega na račun zasebnega ter živi konflikt med svobodo in zakonom. Kar je bil mit v antiki - tu Eagleton sledi vsaj Benjaminu - je v sodobnosti tragedije prevzela zgodovina. Slednja je Eagletonu pomembna zaradi tega, ker tragedija išče (večno neulovljivo) resnico, ki je pa pravzaprav nedosegljiva, saj lahko ljudje iz nevednosti pridejo samo do delne vednosti. In ker je mogoče odločitve človeka ovrednotiti le za nazaj - tu Eagleton spet spregovori s Critchleyevimi besedami -, ostaja vseskozi prisoten prepad med preteklostjo in sedanjostjo, med ne-čisto-racionalnim delovanjem in ne-čisto-funkcionalnim vrednotenjem. Posameznikov jaz je tako subjekt in sam svoj objekt, svoboden in ne-svoboden, individualen in družben hkrati. Za vsak svoj uspeh posameznik plača ceno, zato, v nasprotju 
s Steinerjem, Eagleton razglasi krščanstvo in marksizem za tragični doktrini. V obeh primerih je cena neizmerna in neizmerljiva, saj obe doktrini zahtevata najvišje subjektivno žrtvovanje za srečo drugih. Obe ponujata eshatološko prednost, vendar je cena zanjo absolutna. Dejstvo je namreč, da je harmonija le redko posledica človekovega ravnanja, saj je razdor bližji naši naravi in našim dejanjem, zato je tragedija edina do obisti iskrena osvestitev posledic človekovega početja. Skladno s tradicionalno teorijo od Schillerja do Heideggerja (prim. Eagleton, Tragedy 158) naj bi tragedija spore gladila v spravo. Zato Eagletona ni mogoče uvrstiti med sodobne teoretike, ki ne verjamejo, da je to zares mogoče in tragedijo predstavljajo kot neke vrste politično homeopatijo. Moderna tragedija je tudi po njegovem mnenju mutirala: obrnila se je v človekovo notranjost. $V$ sodobnosti zato ni treba narediti ničesar posebnega, da bi se znašli v tragediji, saj se tudi danes, podobno kot antični junaki, lovimo med namenom, skrivnostjo in pomenom našega bivanja.

\section{Koda}

Ko sklepamo pričujoči pregled odmevnejših teorij tragedije in tragičnega, ugotavljamo, da pravzaprav ne izkazujejo nič novega. Sodobne individualne teorije tragedije se od preteklih (iz vsaj zadnjih dvesto let) razlikujejo po tem, da med njihovimi cilji ni oblikovanja absolutne in večne teorije, temveč so njihovi cilji omejeni. Zgodovinska izkušnja je že dokazala, da je generalizirati tragedijo, kar počnejo nekateri teoretiki, dejansko problematično, saj ta ni preprosto le afirmativna ali negativna, optimistična ali pesimistična, običajna ali tragična. Zato tudi teorija tragedije ne premišljuje več ustrezno in njenih klasičnih predpostavk, imanentne junakove tragičnosti, prisotnosti absolutne usode, nujne sprave oziroma harmonije, vsebnosti mita ali zgodovine itd. ni mogoče več neomahljivo zagovarjati. Tako se zdi, kar so dokazala tudi obravnavana dela, da je sodobna analiza tragedije (in tragičnega) ustreznejša, če je opravljena iz individualnega zornega kota, pa naj je ta čisto filozofsko teoretičen (Menke, Eagleton in Critchley), zgodovinski (Billings, Fischer-Lichte in Young) ali uprizoritven (Lehmann) itd. in s sebi lastno optiko, pristopom in problematiko.

Šele tako se namreč izkaže, da vsi ti različni pristopi govorijo o eni in isti stvari in da jih vse združuje dejanski fenomen človekove eksistence. Tragedija kot pojav je preveč človeška, da bi ji bilo mogoče vnaprej predpisati teoretično definicijo za vse večne čase. Je tudi preveč raznolika, da bi jo lahko ukalupljali v tem ali onem zgodovinskem trenutku in ima 
preveč potencialnih sporočil, da bi v njej lahko iskali eno prevladujočo idejo. Vendar pa je prav na podlagi te raznoterosti obravnav človekovega položaja mogoče uzreti osnovo za izhodišče tragičnega: conditio humana. Tragedija predstavlja enega bolj domišljenih (estetskih) načinov iskanja smisla v človekovem ravnanju, a ravno neuspeh literarne tragedije kot njene definicije razkriva, da smisla ne samo ni mogoče določiti, ampak ga v bistvu ni. Naj se človek še tako trudi, da bi ga našel, naj si še tako prizadeva določiti pomen in vrednost svojim akcijam, jim tega ni mogoče ne predpisati ne pripisati, saj bodo njihovo vrednost določili šele njihovi konteksti ex post, pri čemer so še ti relativni. Ne gre za bivanje med svobodo in nujnostjo, med relativnostjo in absolutom, med ciljem in načrtom, kako do njega. Osnovna predispozicija človekovega bivanja se s tem izkaže kot kontingenčna. Tragično je bistvo dejstva, da človek obrača, bog pa (če sploh, seveda) obrne. Človekova bit je kot absolutno brezciljen Sizifov trud. Začenjamo svoje akcije, zaganjamo se vanje, ker drugače ne moremo, čeprav vemo, da rezultatov ne moremo napovedati, dokler ne bo že prepozno. »Kaj se mi bo zgodilo? Kako lahko izberem pravo pot?« so vprašanja (zastavil si jih je tudi Critchley, prim. Critchley, Tragedy 4), ki nas definirajo. Odpravimo se na pot, ne da bi vedeli kam, kod in po kaj. Ne vemo tudi, kako se bo končala. V najboljši veri in z zaupanjem hodimo po njej, dokler šele na koncu, kot na primer Ojdip, ne ugotovimo, da smo se zmotili, da smo zgrešili. Pa ne zaradi svoje hybris, temveč zgolj zaradi tega, ker smo ljudje. In poleg brezizhodnosti ima to stanje še eno lastnost: nerazrešljivost (o tem sem leta $2004 \mathrm{v}$ delu Privlačna usodnost: subjekt in tragedija spregovoril tudi sam). Ne početi nič je namreč enako slabo kot početi nekaj, oboje ima svoje vnaprej nerazvidne posledice. Kakor koli se torej odločimo, smo soočeni s temeljno teleološko brezizhodnostjo in nerazrešljivostjo svoje eksistence.

Svoje človeško stanje "nosimo k kot Damoklejev meč nad glavo, zato moramo ugotoviti, da je prišlo do velikanske pomote: tragedija je naša zgodba in zato ne more biti drugega kot živa.

\section{LITERATURA}

Billings, Joshua. Genealogy of the Tragic. Greek Tragedy and German Philosophy. Princeton, NJ: Princeton University Press, 2014.

Critchley, Simon. "I Want to Die, I Hate My Life - Phaedra’s Malaise«. New Literary History 35.1 (2004): 17-40.

Critchley, Simon. Tragedy, the Greeks and Us. London: Profile Books, 2019.

Dokler, Anton. Grško-slovenski slovar. Ljubljana: Knezoškofijski zavod Sv. Stanislava, 1915. 
Eagleton, Terry. „Commentary«. New Literary History 35.1 (2004): 151-159.

Eagleton, Terry. Sweet Violence. The Idea of the Tragic. Oxford: Blackwell Publishing, 2003.

Eagleton, Terry. Tragedy. New Haven, CT; London: Yale University Press, 2020.

Fischer-Lichte, Erika. Tragedy's Endurance. Performances of Greek Tragedies and Cultural Identity in Germany since 1800. Oxford: Oxford University Press, 2017.

Kos, Janko. »K vprašanju o bistvu tragedije«. Primerjalna književnost 19.1 (1996): 1-16.

Kos, Janko. »Problem slovenske tragedije». Sodobnost 24.8/9 (1976): 727-738.

Kozak, Krištof Jacek. Privlačna usodnost: subjekt in tragedija. Ljubljana: MGL, 2004.

Lehmann, Hans-Thies. »Postdramatische Tragödie. Anmerkungen zum Theater von Tadeusz Kantor«. Kunst ist ein Verbrechen. Tadeusz Kantor, Deutschland und die Schweiz. Ur. Uta Schorlemmer. Nürnberg: Verlag Für Moderne Kunst, 2007.

Lehmann, Hans-Thies. Tragödie und dramatisches Theater. Berlin: Alexander Verlag, 2013.

Lehmann, Hans-Thies. "Tragödie und Performance: Skizzen aus einem work in progess". Theater des Fragments. Performative Strategien im Theater zwischen Antike und Postmoderne. Ur. Anton Bierl idr. Bielefeld: Transcript-Verlag, 2009. 165-182.

Lehmann, Hans-Thies. "Tragödie und postdramatisches Theater". Tragödie Trauerspiel - Spektakel. Ur. Bettine Menke in Christoph Menke. Berlin: Theater der Zeit, 2007. 213-229.

Lewis, Rhodri. »Man of Sorrows: On Terry Eagleton’s 'Tragedy’. Splet 7. 2. 2021. $<$ https://lareviewofbooks.org/article/man-of-sorrows-on-terry-eagletons-tragedy/>

Menke, Christoph. Die Gegenwart der Tragödie. Versuch über Urteil und Spiel. Frankfurt am Main: Suhrkamp Verlag, 2005.

Platon. "Zakoni«. Zbrana dela I. Celje: Mohorjeva družba, 2006.

Snoj, Vid, Janko Kos, Lado Kralj in Gorazd Kocijančič. "Smrt tragedije: pogovor o knjigi Georgea Steinerja». Primerjalna književnost 26.1 (2003): 95-114.

Steiner, George. "A Note on Absolute Tragedy«. Journal of Literature \& Theology 4.2 (1990): 147-156.

Steiner, George. Smrt tragedije. Ljubljana: LUD Literatura, 2002.

Steiner, George. »'Tragedy,' reconsidered«. New Literary History 35.1 (2004): 1-15.

Young, Julian. The Philosophy of Tragedy. From Plato to Žižek. Cambridge: Cambridge University Press, 2013.

Williams, Raymond. Modern Tragedy. London: Chatto and Windus, 1966. 


\section{From the Museum of Literary Archeology: Is Tragedy a Petrified Fossil or a Living Dinosaur?}

Keywords: literary genres / tragedy / postdramatic theatre / tragic subject / tragic action / fate / guilt

One of the central views on tragedy as an artistic genre in twentieth century is represented by Steiner's popular assumption of the death of tragedy. Original and persuasive, it created the impression that the genre and its related human experience were coming to a closure. The last fifty years when post-dramatic practices developed in the performance studies seem to merely confirm Steiner's hypothesis. Yet, regardless of this, the debate over the tragedy has been going on with a swing. The new millennium proved to be particularly fruitful when some of the most important theorists, such as T. Eagleton, E. FischerLichte, H.-T. Lehmann, and even S. Critchley joined the debate. From their own idiosyncratic points of view-experiential, historical, philosophical, artistic - the results of their conclusions were unequivocal: tragedy continues to exist. In their analyses, presented in this article, they address traditional concepts such as myth and (hi)story, hero and subject, fate and guilt, freedom and necessity, and develop the thesis that tragedy-literally or figurativelyundoubtedly is an attribute of the human condition-since "man proposes, God disposes«. Tragedy, even modern, describes the human condition when human being choses an action of which the outcome he/she does not know. All he/she has is a faith and blind self-confidence.

1.02 Pregledni znanstveni članek / Review article

UDK $82.0-21$

DOI: https://doi.org/10.3986/pkn.v44.i2.08 